SISTEMA
ELETRONICO
DE REVISTAS
SER I UfPR

\title{
Entre Santos, Encantados e Orixás: uma jornada pela diversidade dos sítios naturais sagrados no Brasil
}

\section{Among Saints, Enchanted and Orixás: a journey through the diversity of sacred natural sites in Brazil}

\author{
Erika FERNANDES-PINTO ${ }^{1 *}$, Marta de Azevedo IRVING ${ }^{2}$ \\ ${ }^{1}$ Instituto Chico Mendes de Conservação da Biodiversidade (ICMBio), Brasília, DF, Brasil. \\ ${ }^{2}$ Universidade Federal do Rio de Janeiro (UFRJ), Rio de Janeiro, RJ, Brasil. \\ *E-mail de contato: snsbrasil@gmail.com
}

Artigo recebido em 31 de dezembro de 2017, versão final aceita em 8 de julho de 2018.

RESUMO: Nas últimas décadas, o reconhecimento dos múltiplos valores da natureza vem se ampliando nos debates internacionais sobre estratégias de conservação ambiental - incluindo aqueles considerados culturais. Nesse contexto, os denominados sítios naturais sagrados, reconhecidos em diversas partes do planeta, vêm ganhando visibilidade crescente como um tema-chave na perspectiva da reconexão entre sociedade e natureza. Em meio a um substancial conjunto de informações mundiais sobre o tema, chama atenção que sejam raras as referências a sítios brasileiros, país de grande riqueza biológica e cultural. Diante desse quadro, este artigo objetiva ilustrar a diversidade desses sítios no Brasil, suas principais características e implicações socioambientais, avaliando como essa temática vem sendo abordada nas pesquisas nacionais. A análise baseiase em levantamento bibliográfico e documental, impulsionado por uma estratégia colaborativa de construção de conhecimento. Os resultados revelam que a recorrência da manifestação desse fenômeno nas diversas regiões do país, bem como a sua importância para muitos grupos sociais, contrastam com o seu incipiente reconhecimento nas políticas públicas. As informações sobre o tema estão, em sua maior parte, dispersas em referências não indexadas sobre estudos que permeiam várias áreas de conhecimento, em geral desconectados do debate internacional. A reflexão indica a necessidade de avançar no reconhecimento da interdependência entre cultura e natureza, a partir de investigações interdisciplinares pautadas em abordagens teóricas capazes de promover o diálogo entre conhecimento científico e sabedoria popular, desconstruindo essas dicotomias. Por fim, lança-se um convite à formação de alianças que contribuam com a missão de desvelar os encantos e os mistérios das dimensões sagradas da natureza na terra brasilis.

Palavras-chave: lugares sagrados; valores culturais e espirituais; pesquisa colaborativa; conservação da natureza; espiritualidade ecológica. 
ABSTRACT: Recognition on the multiple values of nature has been increasing in the recent decades in global forums on strategies for environmental conservation- including those considered as cultural. The so-called sacred natural sites, recognized in various parts of the world, have been gaining visibility as a key theme in the perspective on reconnecting society and nature. Amidst a substantial body of world information on the subject, it is noteworthy that references to sites in Brazil (a country of great biological and cultural wealth) are rare. In view of this situation, this article aims to illustrate the diversity of these Brazilian sites, its main characteristics, and socioenvironmental implications, evaluating how this theme has been approached in national surveys. The analysis was based on a bibliographical and documentary survey, driven by a collaborative strategy of knowledge construction. The results show that the recurrence of the manifestation of this phenomenon in the different regions of the country and its importance for many social groups contrast to its incipient recognition in public policies. Information on the subject is, for the most part, dispersed in non-indexed references to studies that permeate various areas of knowledge, often disconnected from the international debate. The reflection indicates a need to recognize the interdependence between culture and nature, based on interdisciplinary investigations and on theoretical approaches capable of promoting dialogue between scientific knowledge and popular wisdom, deconstructing these dichotomies. Finally, we launch an invitation to form alliances that contribute to the mission of unveiling the enchantment and mysteries of nature's sacred dimensions in Brazil.

Keywords: sacred places; cultural and spiritual values; collaborative research; nature conservation; ecological spirituality.

Todos os estudiosos que percorreram o Brasil [...] se apaixonaram pela riqueza das suas possibilidades infinitas. Eminentes geólogos definiram-lhe os tesouros do solo e naturalistas ilustres the classificaram a fauna e a flora, maravilhados ante as suas prodigiosas surpresas [...]. Afãs, todo esse espírito analítico não passou da esfera superficial das apreciações, porque não viram o Brasil espiritual [...] em cujas estradas, cheias de esperança, luta, sonha e trabalha o povo fraternal e generoso (Chico Xavier).

\section{Introdução}

Nas últimas décadas, o reconhecimento dos múltiplos valores da natureza e das suas contribuições (diretas ou indiretas) para o bem-estar e a qualidade de vida humana vem se ampliado nos fóruns mundiais sobre políticas públicas de conservação ambiental. Entretanto, ainda é possível observar nesses debates - uma tendência a evidenciar a importância da natureza em termos de manutenção da riqueza biológica e dos seus benefícios econômicos, em argumentações nas quais predomina a exposição de aspectos cientificistas ou utilitários (Harmon \& Putney, 2003).

No entanto, por mais relevantes que esses aspectos possam ser, eles aparentam ter pouca relação com as razões pelas quais as pessoas de fato se importam com a natureza. Há uma outra arena de valores não materiais que fazem parte dos saberes e da visão de mundo de diversos grupos sociais, conformando ligações culturais e simbólicas com os elementos naturais, ainda pouco compreendidas, subvalorizadas e, muitas vezes, desconsideradas nas estratégias de gestão ambiental (Verschuuren et al., 2010). 
Esses valores estão frequentemente associados a locais específicos - como montanhas, vulcões, cavernas, rios, lagos, matas, árvores, pedras, entre outros -, considerados por grupos humanos como templos ou santuários naturais, dotados de uma energia ou força especial que os distingue da paisagem circundante. Comumente envoltos em uma aura de mistério e magia, esses lugares encantados vêm sendo referenciados na literatura especializada como sitios naturais sagrados (SNS) ${ }^{1}$, entendidos como "áreas de terra ou de água com um significado espiritual especial para povos e comunidades" (Wild \& McLeod, 2008, p. 20).

O sentimento religioso e a busca pelo transcendente são tidos como características inerentes a povos de todos os tempos e culturas (Eliade, 2010). Em que se pesem as profundas mudanças pelas quais a humanidade tem passado ao longo de sua trajetória, a espiritualidade continua a influenciar o pensamento e as atividades sociais cotidianas, não necessariamente como um aspecto formal e institucionalizado, mas também como a crença em algo que ultrapassa a materialidade do mundo, com profundas implicações na forma como as pessoas percebem e interagem com a natureza (Boff, 2008).

Essas temáticas, que podem ser consideradas não convencionais e ainda pouco abordadas em pesquisas acadêmicas - onde, não raro, são também alvo de desqualificação -, vêm sendo promovidas em eventos realizados por instituições globais como a Organização das Nações Unidas para a Educação, a Ciência e a Cultura (UNESCO) e a União Internacional para a Conservação da Natureza (IUCN) e, também, com a publicação de diversas obras de referência. Em meio a esse debate, os SNS, reconhecidos em diversas partes do planeta, têm ganhado visibilidade crescente como um tema-chave na perspectiva da reconexão entre sociedade e natureza e do resgate da sacralidade dessa relação (Fernandes-Pinto \& Irving, 2017).

Nesse contexto, algumas organizações vêm promovendo estudos de caso e a compilação de informações sobre SNS em diferentes regiões do globo, o que tem permitido traçar um panorama geral sobre a situação e a relevância dessas áreas na contemporaneidade (Thorley \& Gunn, 2007; Verschuuren et al., 2010). Considerando que muitos desses sítios estão ameaçados e sujeitos a diversas pressões, as recomendações internacionais formuladas sobre o tema, nos últimos anos, têm alertado para a urgência de se promover ações concretas de proteção dos SNS em seus contextos locais. Todavia, apesar do amplo debate mundial, em grande parte dos países o conhecimento sobre essa problemática ainda é limitado e as iniciativas de mapeamento e salvaguarda dessas áreas em políticas públicas nacionais são escassas (Wild \& McLeod, 2008).

Esse parece ser o caso do Brasil, um país "gigante pela própria natureza"2 que, com sua vasta dimensão territorial e variedade de ambientes, conjuga uma das maiores riquezas biológicas do mundo a uma expressiva pluralidade sociocultural. Estima-se que nele ocorram $40 \%$ das florestas tropicais e $14 \%$ das espécies de plantas e animais do planeta (Lewinsohn \& Prado, 2005). Aliada à exuberância natural, o país também abriga cerca de 250 etnias indígenas (Ricardo \& Ricardo, 2017) e centenas de

\footnotetext{
${ }^{1}$ Uma tradução direta da expressão original em inglês, sacred natural sites.

${ }^{2}$ Trecho do Hino Nacional Brasileiro, de autoria de Joaquim Osório Duque Estrada, de 1971.
} 
populações tradicionais representadas por um diversificado conjunto de grupos sociais de múltiplas origens, com modos de vida adaptados a determinados ambientes. Além disso, o Brasil recebeu, ao longo de sua história, fluxos de imigrantes oriundos de diversos países, favorecendo a formação de uma nação multicultural que se destaca também por uma rica diversidade religiosa (Neri, 2011).

Considerando essas características do país e o fato dos SNS serem uma expressão da conjugação entre natureza e cultura (Verschuuren et al., 2010), chama a atenção que - em meio a um substancial corpo de publicações e bases de dados globais sobre a temática - sejam raras as referências ao contexto brasileiro. Como explicar, então, essa aparente lacuna de informações sobre o Brasil no debate internacional? Quais são os principais sítios sagrados do país e suas características? Eles vêm sendo objeto de estudos e/ou iniciativas de salvaguarda?

Esses questionamentos inspiraram a condução de uma investigação exploratória sobre o tema e a elaboração desse artigo, que objetivou ilustrar a diversidade dos SNS no território brasileiro, suas principais características e implicações socioambientais, avaliando como essa temática vem sendo abordada nas pesquisas nacionais. A análise foi baseada em levantamento bibliográfico e documental, impulsionado por uma estratégia colaborativa de construção de conhecimento, detalhada a seguir.
São tecidas, inicialmente, considerações sobre a metodologia utilizada para "descobrir" os sítios brasileiros e reflexões conceituais sobre a expressão sítios naturais sagrados. Na sequência, adentra-se no rico universo dos SNS no Brasil, evidenciando exemplos emblemáticos. Por fim, ao avaliar a abordagem do tema nas pesquisas nacionais, busca-se identificar os principais desafios para a proteção e valorização desse patrimônio no contexto brasileiro. A interpretação dos resultados foi orientada pela ancoragem teórica da Psicossociologia e da Ecologia Social, na perspectiva de ir além do simples nível factual do fenômeno, compondo uma visão interdisciplinar e crítica da problemática na contemporaneidade.

\section{O desafio de descobrir os sítios naturais sagrados do Brasil}

Em complemento à consulta a anais de eventos de referência sobre o tema, promovidos pela UNESCO e UICN nas últimas décadas ${ }^{3}$, e a bases de dados mundiais de registro de $\mathrm{SNS}^{4}$ - conforme mencionado anteriormente -, foi realizada uma pesquisa bibliográfica em portais eletrônicos nacionais e latinoamericanos de documentação científica ${ }^{5}$,

\footnotetext{
${ }^{3}$ Simpósios internacionais realizados em Paris (1998), na China (2003) e no Japão (2005); e workshops da Delos Initiative realizados na Espanha (2006), na Grécia (2007) e na Finlândia (2010) - anais disponíveis em: https://csvpa.org. Para uma cronologia dos eventos mundiais relacionados à temática dos SNS e contextualização dos principais marcos e tendências da discussão internacional sobre o tema, recomenda-se o artigo Sítios naturais sagrados: valores ancestrais e novos desafios para as políticas de proteção da natureza (Fernandes-Pinto \& Irving, 2017).

${ }^{4}$ Sacred Natural Sites Initiative (<sacrednaturalsites.org $>$ ), Places of Peace and Power (<sacredsites.com $>$ ), Sacred Land Film Project $(<$ sacredland.org $>$ ), Gaia Foundation ( $<$ www.gaiafoundation.org $>$ ), Alliance of Religions and Conservation $(<$ www.arcworld.org $>)$, Delos Initiative (<www.med-ina.org/delos/>), The World Database on Sacred Natural Sites (<www.sanasi.org $>$ ) e Silene Documentation Center $(<$ www.silene.es $>$ ).

${ }^{5}$ No Portal de Periódicos da Coordenação de Aperfeiçoamento de Pessoal de Nível Superior (<www.periodicos.capes.gov.br>) e no Scientific Eletronic Library Online (<www.scielo.br $>$ ).
} 
almejando inventariar registros sobre esses sítios no Brasil.

Para tanto, diversas palavras-chave associadas ao tema foram conjugadas nos mecanismos de consulta dos portais elencados, combinando os termos que compõem a expressão sitios + naturais + sagrados com descritores semelhantes e alternativos ${ }^{6}$. Como critério para inclusão na pesquisa, foram selecionadas as referências que se reportavam - ainda que pontualmente - a elementos naturais do território nacional aos quais se atribui significados simbólicos, religiosos e/ou espirituais.

Os resultados preliminares desse levantamento foram sintetizados no trabalho intitulado Sítios $\mathrm{Na}$ turais Sagrados no Brasil: o gigante desconhecido (Fernandes-Pinto \& Irving, 2015a), apresentado no VII Seminário sobre Áreas Protegidas e Inclusão Social - SAPIS 7 . Essa compilação inaugural de informações sobre o tema, além de registrar 60 SNS no país, permitiu identificar uma série de limitações na busca de referências por meio dos mecanismos usuais de pesquisa bibliográfica em bases científicas. Verificou-se que esses registros estavam em grande parte dispersos em estudos de diversas áreas do conhecimento e que a ausência de padronização de descritores e palavras-chave ${ }^{8}$ dificultava a identificação, seleção e triagem das referências. Em função disso, a detecção da maior parte das informações compiladas demandou não apenas a triagem a partir dos títulos e resumos das publicações, mas principalmente a busca no corpo textual dos documentos - um esforço realizado à semelhança de uma garimpagem.

Diante dessas dificuldades, para avançar na proposta de descobrir os sítios naturais sagrados do território nacional, foi desenvolvida uma estratégia de pesquisa colaborativa intitulada Rede SNS Brasil. Lançada no evento mencionado anteriormente (VII SAPIS), essa iniciativa foi concebida com o objetivo de dar visibilidade ao tema no país e aprofundar o conhecimento sobre os seus sítios sagrados, agregando contribuições de pesquisadores de diversas áreas do conhecimento, gestores públicos e representantes de movimentos sociais ou espiritualistas e compartilhando-as com o auxílio de ferramentas de mídias sociais?.

A combinação dessas estratégias permitiu diversificar as fontes de informação sobre o tema-incluindo resultados de buscas em portais generalistas como o Google, acervos físicos de bibliotecas, páginas de grupos de pesquisa, redes sociais acadêmicas (como o Research Gate e o Academia.edu) e contato direto com especialistas -, resultando na compilação de cerca de 400 referências e no registro de mais de 480 SNS no território nacional ${ }^{10}$.

Como não seria possível descrever, no escopo de um artigo, todos os sítios mapeados, buscou-se

\footnotetext{
${ }^{6}$ A palavra sitio, por exemplo, foi combinada com lugar, local, área, caverna, montanha e santuário; o vocábulo natural, com natureza e ambiente; e o termo sagrado, com místico, misterioso, mágico, curativo, religioso, milagroso, santo, esotérico e encantado - incluindo variações plural e feminino.

${ }^{7}$ Evento realizado em novembro de 2015, em Florianópolis/SC.

${ }^{8}$ Descritores são vocábulos padrões que expressam conceitos chave de áreas de conhecimento, definidos pelos veículos indexadores, enquanto palavras-chave são termos representativos do assunto do documento propostos pelos autores. Esses quesitos são a base do processo de indexação, possibilitando identificar e selecionar uma publicação a partir da descrição do seu conteúdo temático (UFPR, 2007).

${ }^{9}$ Particularmente o Facebook (www.facebook.com/sitiosnaturaissagrados/) e o Pinterest, (br.pinterest.com/snsbrasil/). Para participar da Rede enviar solicitação para snsbrasil@gmail.com.

${ }^{10}$ Esses resultados incluem o material processado até julho de 2017.
} 
ilustrar a variedade de tipologias, significados e usos desses espaços, a partir de exemplos emblemáticos, destacando alguns elementos fundamentais para a compreensão desse fenômeno no território nacional ${ }^{11}$. Antes de adentrar nesse universo, entretanto, é pertinente tecer algumas considerações acerca dos entendimentos conceituais sobre o tema e os critérios adotados para considerar, ou não, um determinado local como um SNS, conforme exposto a seguir.

\section{Sobre a (in)definição de sítios naturais sagrados}

Atribuir significados simbólicos ou espirituais a determinados lugares na natureza vem sendo relatado como uma característica comum a diversos grupos humanos ao longo da história, uma prática ancestral propagada por todo o mundo e ainda presente em muitas regiões na contemporaneidade. Conforme abordado anteriormente, na literatura especializada eles vêm sendo reportados como sacred natural sites (SNS) - expressão adotada por diversos autores e que vem se consolidando no debate mundial sobre políticas públicas, abarcando um conjunto heterogêneo de possibilidades. Esse termo, entretanto, surgiu somente no início dos anos $2000^{12}$ e não marca, necessariamente, a origem dos estudos sobre esse assunto amplo e complexo.
Ainda que a primazia autoral da expressão SNS não seja muito clara ${ }^{13}$, ela passou a ter visibilidade no cenário global com os trabalhos do Specialist Group for Cultural and Spiritual Values of Protected Areas (CSVPA), vinculado à Comissão Mundial de Áreas Protegidas da IUCN. E, particularmente, com a publicação das diretrizes de boas práticas intitulada Sacred Natural Sites: Guidelines for Protected Area Managers (Wild \& McLeod, 2008), em uma parceria da UNESCO com a IUCN - uma das principais referências sobre o assunto.

Diante da advertência de Weber (2004, p. 36) de que "tudo depende do que se entenda pelas palavras empregadas", é importante ressaltar que os três termos que compõem a expressão - sites, natural e sacred - podem ter significados diferentes dependendo do contexto em que são utilizados, resultando em diversas nuances na sua interpretação. Como mencionado anteriormente, os SNS podem estar relacionados com uma ampla variedade de feições morfológicas - de uma única pedra ou árvore até formações florestais e cordilheiras inteiras -, de forma que delimitar um sitio como um elemento em particular nem sempre é possível. Além disso, o fato dos lugares dotados de valores religiosos serem frequentemente consagrados com artefatos humanos também torna a distinção como natural problemática. A inclusão desse vocábulo na terminologia sacred sites, utilizada inicialmente,

\footnotetext{
${ }^{11}$ A lista completa dos SNS registrados nesse levantamento e suas referências constam na Tese de Doutorado de Fernandes-Pinto (2017), disponível em: https://goo.gl/ZNCE11.

${ }^{12}$ O V World Parks Congress, realizado pela IUCN em Durban/África do Sul, em 2003, é considerado o marco inicial do debate internacional sobre o tema, especialmente no tocante ao reconhecimento dos valores culturais e espirituais das áreas protegidas. A primeira resolução especificamente sobre sacred natural sites, no entanto, foi aprovada somente em 2008, no World Conservation Congress de Barcelona/Espanha.

${ }^{13}$ A cunhagem desse termo na literatura especializada é frequentemente atribuída a Thomas Schaaf, pesquisador vinculado ao Programa Homem e Biosfera da UNESCO, que coordenou projetos pioneiros sobre o tema. As primeiras publicações internacionais a conter a expressão no título, entretanto, até onde foi possível pesquisar, são referentes a um workshop realizado em Paris, em 1998 (UNESCO, 1998) e o concept paper da iniciativa internacional para a proteção de SNS implementada pelo World Wide Life Fund (Jeanrenaud, 2001).
} 
entretanto, foi justificada por alguns autores como uma estratégia para diferenciar, por exemplo, uma catedral de uma caverna (Thorley \& Gunn, 2007).

Essas dificuldades conceituais com relação aos termos site e natural, entretanto, não se comparam à multiplicidade de perspectivas e complexidade teórica que acompanha o vocábulo sacred. Este, muitas vezes, não tem sequer um equivalente nas línguas nativas para povos que não reconhecem a separação entre natureza e cultura, entre material e imaterial ou do sagrado e do profano. Diante dessas questões, Carmichael et al. (1994) propuseram que, ao invés de se buscar uma definição única para o termo, ele fosse utilizado como uma palavra-chave abrangente dos diversos significados atribuídos aos SNS pelos próprios grupos culturais. Foi nessa direção também que Schaaf (2003) justificou o emprego de sacred com um sentido genérico e não necessariamente religioso.

Para Eliade (2010) - um influente estudioso da História das Religiões e autor da obra clássica de referência sobre o tema, O Sagrado e o Profano: a essência das religiões (publicada originalmente em 1957) - o sagrado implica em estar diante de algo diferente, proveniente de uma realidade que não pertence à percepção ordinária, mas que se manifesta no mundo físico constituindo hierofanias. Essa ideia remete a algo que existe $a$ priori, antes mesmo da experiência acontecer, ou seja, a cultura não o cria, apenas o reconhece. Assim, o sagrado se distingue da noção do divino - uma ideia teísta que busca dar um contorno racional à divindade, a partir de atributos humanos como amor, bondade e fé. A experiência do sagrado, por outro lado, ultrapassa o domínio do intelectual, não sendo - portanto explicável, somente vivenciável.
Para além das polêmicas acadêmicas, a riqueza de termos vernáculos ou nativos utilizados para se referir aos SNS possivelmente seja tão vasta quanto a diversidade de grupos sociais que os reconhecem (Thorley \& Gunn, 2007). De forma geral, pode-se considerar este como sendo um conceito ético empregado por agentes externos para se referir a determinados elementos das culturas pesquisadas - enquanto os nomes dados localmente a esses lugares seriam conceitos êmicos - criados pelos grupos sociais a partir de suas categorias culturais próprias (Marques, 2001).

Diante das múltiplas situações representadas pelos SNS, também são inúmeras as dificuldades para a formulação de uma definição que exprima esse conceito adequadamente. Esse seria o principal motivo, conforme indicam alguns autores, para uma aparente ausência de formulações acadêmicas da expressão (Thorley \& Gunn, 2007). As publicações sobre o tema partem, em geral, de definições operacionais genéricas ou provenientes do senso comum, sem derivá-las de uma construção teórica mais elaborada e remetendo a identificação dos seus parâmetros aos grupos a eles relacionados. Assim, mais do que um conceito, pode-se dizer que a expressão SNS vem sendo utilizada na literatura especializada e nos debates internacionais como um rótulo para caracterizar um espectro diversificado de possibilidades como objetos de estudos e de aplicação de políticas públicas.

No contexto desse trabalho, conforme abordado anteriormente, foi adotada a noção de SNS preconizada nos documentos oficiais da UNESCO e da IUCN (Wild \& McLeod, 2008). Assim, foram considerados como SNS no Brasil lugares relacionados a diversos grupos sociais, tradições religiosas e linhas espiritualistas (institucionalizadas ou 
não), independentemente de estarem relacionados a algum tipo de reconhecimento formal. Foram incluídos tanto lugares estritamente naturais (sem intervenções antrópicas diretas), como também aqueles aos quais foi acrescido algum construto humano, desde que instalados em função da sua consagração, conforme será detalhado com os exemplos apresentados a seguir.

\section{Sítios naturais sagrados do Brasil: revelando o gigante desconhecido}

Representados por uma ampla gama de tipologias de elementos naturais, os SNS no Brasil incluem ao menos 122 cavidades naturais, 104 elevações montanhosas, 99 corpos hídricos, 50 formações rochosas, 30 matas e/ou espécies de árvores, 30 formações costeiro-marinhas, 30 caminhos de peregrinações e, ainda, 21 localidades ou regiões. Esses sítios estão distribuídos por todos os estados da Federação, tanto em áreas rurais como em núcleos urbanos, associados a múltiplas práticas religiosas e manifestações culturais. Alguns sítios são consagrados nacionalmente, atraindo visitantes de várias partes do Brasil e do mundo, enquanto outros são conhecidos apenas localmente. Existem, ainda, aqueles envoltos pelo segredo, cuja localização e/ou função religiosa é de domínio apenas de um número limitado de indivíduos.
As referências analisadas incluem lugares sagrados reconhecidos por diversos grupos sociais, tanto povos indígenas (relacionados a 82 sítios) e outras populações tradicionais (incluindo quilombolas, seringueiros, ribeirinhos, quebradeiras de coco-babaçu, pescadores artesanais, sertanejos, entre outros, com 67 sítios) como para linhas religiosas/espiritualistas. Dentre estas, destaca-se o catolicismo - religião majoritária no Brasil, adotada por $64 \%$ da população - com 234 sítios; as religiosidades alternativas ${ }^{14}$ om 84 sítios; as tradições de matriz afrobrasileira ${ }^{15}$ com 68 sítios; o neopentecostalismo ${ }^{16}$ com 21 sítios; e filosofias orientais - particularmente o budismo, considerada a mais relevante das religiões minoritárias seguidas no Brasil (Neri, 2011) - com 4 sítios.

Alguns SNS estão vinculados a sítios arqueológicos com vestígios de uso cerimonial por povos pré-históricos e a monumentos megalíticos - conjuntos de antigas e enigmáticas formações rochosas (22 sítios). É importante destacar também que cerca de $15 \%$ dos SNS registrados nesse levantamento foram associados a mais de uma linha religiosa ou grupo social, podendo ser considerados de caráter multirreligioso.

As origens e as razões da sacralidade desses sítios são diversificadas, variando de acordo com as suas características naturais e com as crenças dos grupos que os consagram. As narrativas sobre os SNS envolvem desde mitos de origem de povos

\footnotetext{
${ }^{14}$ Um movimento emergente no país, representado por diversas linhas que são vivenciadas como distintas das práticas religiosas ocidentais convencionais, também denominadas de filosofias Nova Era (Siqueira, 2010).

${ }^{15}$ Incluem uma variedade de tradições como o Candomblé (originário da África), a Umbanda (doutrina nascida no Rio de Janeiro, no começo do século XX) e derivações regionais como o Terecô e o Tambor de Mina (presentes no Estado do Maranhão).

${ }^{16}$ Uma vertente recente e dinâmica do evangelicanismo, que surgiu no Brasil na década de 1970 e se configura como a religião que mais cresceu no país nas últimas duas décadas, adotada por cerca de $22 \%$ da população (Neri, 2011).
} 
indígenas, vínculos com divindades ou espíritos ancestrais, relação com eventos significativos na história de um grupo social e/ou episódios marcantes da vida de personalidades veneradas popularmente. São registrados, ainda, SNS que têm relação com alinhamentos astronômicos e manifestação de fenômenos naturais excepcionais, que são fontes de recursos especiais como águas sagradas e plantas de poder, até relatos sobre a existência de portais interdimensionais, de acesso ao mundo intraterrestre, presença de civilizações ocultas e registros ufológicos. Os sítios sagrados também são comumente associados a lendas sobre seres mitológicos - como sereias e dragões -, que tanto encantam como atemorizam o imaginário popular.

Os SNS podem ser palco de diversas práticas associadas à sua sacralidade, tanto eventuais como frequentes - incluindo desde atividades individuais de prece, oração, meditação e contemplação até celebrações coletivas de cultos, missas, batismos, romarias e festividades religiosas. Em função dessas manifestações, alguns SNS se tornaram importantes pólos de turismo regional (Travassos et al., 2011).

No contexto do catolicismo, a natureza comumente representa um pano de fundo para a celebração dos ritos religiosos. Diversos sítios naturais são consagrados com marcos materiais - de pequenos altares, cruzeiros e imagens sacras a grandes estátuas, capelas, igrejas e catedrais. Algumas datas marcam a celebração de eventos especiais que chegam a reunir milhares de pessoas, como a Semana Santa (representação da morte e ressurreição de Jesus Cristo).

No rol de SNS relacionados com o catolicismo no Brasil, destaca-se o complexo religioso das grutas de Bom Jesus da Lapa/BA, um dos maiores santuários subterrâneos do mundo. A celebração mais importante, realizada no local há mais de 300 anos, no mês de agosto, reúne cerca de 600 mil pessoas, nessa que provavelmente seja a mais antiga e maior festividade religiosa relacionada a uma caverna no país (Steil, 1996; Magalhães, 2010). Além dessa, existem dezenas de outras cavidades naturais no território nacional consagradas com ritos católicos, como a Gruta das Mangabeiras/BA e a Lapa de Terra Ronca/GO. Entretanto, registros que relacionam o uso desses ambientes por outras tradições religiosas são escassos.

Além disso, também são diversas as elevações montanhosas no Brasil onde foram erigidos santuários - como o de Nossa Senhora da Piedade, na Serra da Piedade/MG; o de Nossa Senhora das Vitórias, no Monte do Galo/RN; e o de Nossa Senhora Imaculada Rainha do Sertão, no Morro do Urucum/CE. Em outros montes foram instaladas estátuas de figuras santas, como a do Padre Cícero Romão Batista (sacerdote católico de grande devoção popular no nordeste brasileiro) na Serra do Catolé/CE; a de Frei Damião (frade italiano da Ordem dos Capuchinhos, radicado no Brasil na década de 1930), no Alto do Cruzeiro/PE; e a de Santa Rita de Cássia (monja agostiniana conhecida como a madrinha dos sertões), no Monte Carmelo/RN. A mais famosa delas, o Cristo Redentor no Morro do Corcovado/RJ, constitui um expressivo símbolo nacional e um dos principais atrativos turísticos do país (Moutinho-da-Costa, 2008).

Um fenômeno relativamente recente no Brasil, porém significativo, são os denominados montes de oração, vinculados a religiosidades neopentecostais, um movimento em expansão no país, principalmente nos grandes centros urbanos, como a cidade do Rio de Janeiro. Seguindo preceitos bíblicos, para essas tradições, subir determinadas 
elevações naturais tem a conotação de um meio físico de sacrifício em busca da purificação e ascensão espiritual (Maciel \& Gonçalves, 2015).

Muitas elevações naturais de uso religioso constituem refúgios de natureza preservada que se mantiveram conservados sobretudo em função do relevo acidentado, que dificulta a expansão agrícola e o avanço de outras atividades econômicas. Não se pode desconsiderar, no entanto, a exemplo do que vem sendo registrado em outros países, que a importância simbólica a elas atribuída também venha contribuindo para a sua preservação. Essa linha de investigação, entretanto, ainda é rara nas pesquisas realizadas no Brasil (Brito, 2008).

Fontes onde brotam águas tidas como milagrosas também são recorrentes no território nacional. Em uma ampla revisão sobre o tema, Lazzerini \& Bonotto (2014) mapearam 102 localidades no Brasil com afloramentos hídricos relacionados a aspectos míticos, poderes mágicos ou propriedades curativas, energéticas e rejuvenescedoras. Na região sul do país ${ }^{17}$, por exemplo, fontes de água que teriam sido abençoadas pelo monge João Maria de Agostini (padre italiano que peregrinou pelo Brasil entre os anos de 1844 e 1852) ainda figuram no imaginário coletivo e são reverenciadas não apenas pelos adeptos do catolicismo, mas também por indígenas Guarani e Kaingang (Karsburg, 2012).

A realização de procissões terrestres, fluviais, lacustres e marítimas também se constitui em uma prática costumeira em diversos locais (Amado, 2011). Além disso, são encontrados no país vários caminhos sagrados - como os da Luz/MG, do Sol/ SP, da Fé/SP, das Missões/RS e dos Passos de Anchieta/ES. No geral, esses percursos se originam de antigas rotas de peregrinação religiosa que vêm sendo ressignificadas como destinos turísticos a partir do ano 2000, inspirado no mundialmente conhecido Caminho de Santiago de Compostela ${ }^{18}$, incorporando elementos da espiritualidade Nova Era (Steil \& Carneiro, 2008). O Caminho do Peabiru - uma rota transcontinental de cerca de quatro mil quilômetros utilizada pelos povos nativos anteriormente ao período da colonização - também vem ganhando importância turística nos últimos anos (Bond, 2009).

Com relação ao amplo e eclético universo das religiosidades alternativas no Brasil, muitas dessas linhas articulam elementos de várias tradições espirituais clássicas vinculando-os à valorização de uma espiritualidade ecumênica, pautada em processos diretos de transformação pessoal que encontram a sua máxima expressão na interação com a natureza (Carvalho \& Steil, 2008). Nesse contexto, os SNS frequentemente são considerados como chackras planetários ou vórtices irradiadores de energia (Lima, 2005). Essas tradições, em geral, reconhecem a Terra como um organismo vivo ${ }^{19}$, dotada de uma grade de circulação que conecta pontos de alta concentração energética - as denominadas ley

\footnotetext{
${ }^{17}$ Nos estados do Paraná e Santa Catarina, onde ocorreu a Guerra do Contestado (1912-1916), um dos maiores levantes populares da história do Brasil.

${ }^{18}$ É interessante observar que o Brasil é o país não-europeu que mais envia peregrinos à Santiago. Existem associações de amigos desse caminho em diversos estados brasileiros e muitos dos trajetos nacionais parecem ter surgido como oportunidades de treinamento para a travessia do caminho europeu.

${ }^{19}$ Essa visão, que reporta à Teoria de Gaia proposta por James Lovelock, em 1972, tem sido resgatada na contemporaneidade inclusive na formulação de políticas públicas, como na Declaração dos Direitos da Mãe Terra, proposta apresentada à Organização das Nações Unidas em 2010.
} 
lines (Thorley \& Gunn, 2007). Para esses grupos, a ativação de sítios sagrados visa o despertar de uma nova consciência ecológica, vinculada ao restabelecimento da unidade vital entre sociedade e natureza (Amaral, 2000).

A região da Chapada dos Veadeiros, no Planalto Central/GO, consiste em um dos ícones desse movimento, atraindo grupos nacionais e internacionais (Siqueira \& Bandeira, 1998). Na Serra da Mantiqueira/MG, há um circuito turístico de montanhas mágicas certificado pelo Estado (Tavares et al., 2011). O Morro do Japão/MT é considerado a única montanha sagrada budista nas Américas. As montanhas do Rio de Janeiro, permeadas por lendas e mitos indígenas ancestrais, vêm sendo redescobertas pelo movimento espiritualista na contemporaneidade, tornando-se palco de diversas manifestações. A Pedra da Gávea, em particular, com suas formas que instigam a curiosidade de turistas e estudiosos, é cercada de mistérios que a conectam a antigas civilizações e seres extraterrestres (Malta, 2016).

Na Serra do Roncador/MT, o plano de uso público de um parque estadual contemplou a construção de um discoporto (um tipo de "aeroporto para discos voadores"), atendendo à demanda dos diversos grupos de estudos ufológicos existentes na região e vislumbrando também um potencial interesse turístico. As florestas do Alto Rio $\mathrm{Pu}-$ rus guardam a localidade do Céu do Mapiá/AC, nascedouro da doutrina do Santo Daime - uma religião da floresta que faz uso de plantas de poder ou enteogênicas ${ }^{20}$, que do interior da Amazônia se propagou mundialmente (Labate, 2000).
Grandes afloramentos rochosos são comumente vistos por populações tradicionais com respeito e admiração, fazendo parte de diversas tradições que continuam vivas no território nacional (Santos \& Brito, 2011). Os monumentos megalíticos, por exemplo - constituídos por grandes pedras dispostas em posições específicas que evidenciam alinhamentos com os astros - são frequentes ao longo da costa brasileira. Um sítio arqueológico descoberto em 2006, os Cromeleques de Calçoene/AP (um conjunto de 127 blocos de granito dispostos em círculo), vêm se destacando como "a Stonehenge brasileira" - uma referência ao famoso monumento localizado na Inglaterra (Afonso \& Nadal, 2014). Essas formações misteriosas permanecem, ainda na atualidade, envoltas em controvérsias entre pesquisadores quanto à sua autoria, significado e datação, de onde surgem teorias que colocam em cheque a historiografia oficial.

Em Sete Cidades/PI, por exemplo, um dos maiores acervos pré-históricos das Américas compõe um cenário que aguça o imaginário popular. Para Erich von Däniken - autor de Eram os deuses astronautas? (1968) - forças não-naturais atuaram na construção do local. Suas pinturas rupestres foram atribuídas pelo pesquisador francês Jacques de Mahieu aos Vikings e, para o historiador austríaco Ludwig Schwennhagen, os fenícios teriam utilizado esse local para a realização de cerimônias religiosas (Favera, 2002).

Muitas práticas das tradições afrobrasileiras ocorrem em áreas de vegetação nativa, córregos e cachoeiras, o que reflete a importância da natureza preservada como elemento simbólico e místico para

\footnotetext{
${ }^{20} \mathrm{O}$ termo enteógeno significa manifestação do divino interior e tem sido utilizado para se referir a substâncias naturais que induzem a estados de transe, utilizadas como meio de contato com o mundo espiritual e seres divinos (Labate \& Goulart, 2005).
} 
essas religiosidades. Suas divindades, os Orixás, estão intrinsecamente relacionadas com as forças e os fenômenos da natureza (Sobreira \& Machado, 2008). Os rituais realizados por esses grupos em áreas naturais visam o contato com o mundo espiritual, a purificação e a energização pessoal, por meio de práticas que podem envolver cantos e danças, ofertas de alimentos, bebidas, flores ou objetos como - por exemplo - recipientes com água, velas e adornos (Verger, 1999).

Na Floresta da Tijuca/RJ, Malta (2016) espacializou o uso público religioso ao mapear 46 áreas, caminhos ou elementos naturais de significância espiritual. Dezenas de grupos de diferentes religiosidades utilizam essas matas, que fazem parte de um parque nacional, para rituais e celebrações - um exemplo emblemático do caráter multirreligioso que diversas áreas naturais urbanas assumem no país (Guimarães \& Pellin, 2015). Entretanto, é no contexto das práticas de matriz afrobrasileira que emergem os maiores conflitos com a administração pública, principalmente em função da deposição de oferendas na natureza (Moutinho-da-Costa, 2008). Algumas iniciativas de gestão desenvolvidas nessa área vêm buscando aliar o respeito às religiosidades com a conservação ambiental. Setores planejados e geridos coletivamente, por exemplo, foram implementados para assegurar aos praticantes locais adequados para expressão de seus rituais - como o Espaço Sagrado da Curva do S, inaugurado em 2012, e a Cachoeira Sagrada do Rio da Prata, em 2014 (Corrêa et al., 2013).

Para os povos indígenas e diversos grupos de populações tradicionais, a natureza também se constitui no elemento principal de reverência espi- ritual. Na cosmovisão desses grupos, os SNS são comumente percebidos como moradas de espíritos ancestrais e locais dotados de uma força vital poderosa. Alguns sítios se constituem em importantes núcleos de referência para a identidade cultural dos grupos e são centrais na conformação de seus territórios, como marcos de eventos mitológicos ou históricos, palco de contato entre grupos étnicos ou de batalhas contra conquistadores.

Considerado um intrigante e belo fenômeno da natureza na Amazônia brasileira, o encontro das águas pretas e calmas do Rio Negro com as barrentas e turbulentas águas do Rio Solimões que por cerca de cem quilômetros correm juntas sem se misturar -, marca a paisagem e a identidade da população local. Além da beleza cênica, a importância do sítio remete à história da ocupação da região como local de reverência aos antepassados indígenas que ali pereceram em luta pelo território (Corso Neto \& Soares, 2015). Outros SNS estão relacionados com esconderijos ou rotas de fuga que permitiram a sobrevivência de determinados grupos frente à ação de tropas colonizadoras, como a Serra da Barriga/AL, reduto do antigo Quilombo dos Palmares - importante núcleo de resistência formado na história escravagista brasileira, transformado em um parque memorial em 2007 (Correia, 2013).

As Cachoeiras do Iauaretê estão associadas aos mitos de origem de diversos povos indígenas do Alto Rio Negro/AM, marcando o local do surgimento dos seus ancestrais na superfície terrestre depois de uma jornada mítica no bojo da denominada cobra-grande (Andrello, 2012). Na tríplice fronteira do Brasil com a Guiana e a Venezuela, o Monte Roraima/RR - antes de ser considerado o mundo 
perdido $o^{21}$ para a civilização ocidental - é o coração do mundo Ingarikó, uma montanha sagrada também para outros povos indígenas da região (Fernandes-Pinto \& Irving, 2015b). O Pico da Neblina/AM, ponto culminante do Brasil, guarda lugares sagrados relacionados aos espíritos ancestrais Yanomami que protegem o mundo da queda do céu (Kopenawa \& Albert, 2015).

No sertão nordestino, a Serra Negra/PE é um local ancestral de realização do ritual secreto do Ouricuri dos povos Kambiwá e Pipipã (Léo Neto, 2015); tal qual a Serra do Arapuá/PE, para o Povo Pankará (Oliveira, 2014); e a Serra do Umã/PE, para os Atikum (Silva, 2007). Na região costeira do sul da Bahia, o Monte Pascoal é tido como a primeira porção do território brasileiro avistada pela esquadra portuguesa comandada por Pedro Álvares Cabral e considerado, em função disso, como um símbolo do "descobrimento" do Brasil. Essa representação, entretanto, vem sendo contestada pelos Pataxó, que demandam o reconhecimento da ancestralidade indígena nessa área, transformada em um parque nacional (Valle, 2001).

Em contraste com os SNS reconhecidos por religiões institucionalizadas - nos quais são comuns intervenções estruturais para facilitar o acesso e a circulação dos fiéis -, os locais venerados por povos tradicionais tendem a ser mantidos sem ocupação e/ ou intervenções humanas diretas. Alguns sítios somente podem ser visitados em condições especiais ou por indivíduos preparados em ritos iniciáticos ${ }^{22}$.
Há locais reservados unicamente aos seres do plano espiritual, que não devem ser adentrados pelos humanos, sob risco de severas consequências em caso de transgressões (Marques, 1999). Relata-se, ainda, que impedir o acesso dos guardiões tradicionais a essas áreas pode trazer prejuízos também aos lugares sagrados, pois as forças espirituais definhariam caso não fossem abastecidas por meio dos seus rituais e oferendas (Ferretti, 2008).

Diversos lugares no Brasil também são reconhecidos como morada de princesas lendárias (como a Praia de Jericoacoara/CE), reis (como as dunas da Ilha dos Lençóis/MA), sereias (como a Gruta das Encantadas/PR) e outros seres míticos. Na região do Pantanal Matogrossense, Leite (2000, p.3) descreve que os encantados ${ }^{23}$ fazem parte "da vida, dos medos, dos episódios, da memória, das paisagens e da cultura da região". Seus estudos revelam que, no imaginário da população pantaneira, há mundos submersos e sobrenaturais entremeados com o mundo natural. Na avaliação desse autor, no entanto, poucas pesquisas realizadas na região consideraram as relações culturais das populações locais com o ambiente na qual estão inseridas - um cenário que parece se reproduzir nas demais regiões do país.

Ainda são escassas as iniciativas de mapeamento e registro de SNS no Brasil. O Projeto Mapeo de Cartografia Cultural - uma parceria binacional entre o Brasil e a Colômbia, iniciada em 2009 -, identificou vários componentes da paisagem que

\footnotetext{
${ }^{21}$ Uma referência à obra literária de Arthur Conan Doyle - The Lost World, de 1912 -, inspirada nas narrativas dos primeiros exploradores europeus que adentraram essa região e que marca o imaginário popular a ela associado na contemporaneidade.

${ }^{22}$ Considera-se aqui a concepção do termo atribuída por Eliade (2010), de cerimônias e provas que testam o indivíduo e marcam a sua entrada na dimensão do sagrado.

${ }^{23}$ Seres mágicos concebidos como espíritos de homens e mulheres que passaram diretamente desse mundo para um plano mítico - ao que se refere que se encantaram (Prandi, 2004).
} 
constituem elementos centrais dos sistemas cosmológicos dos povos indígenas do noroeste amazônico (Scolfaro et al., 2014). O Projeto Anaconda, realizado a partir de um amplo processo participativo protagonizado pela Federação das Organizações Indígenas do Rio Negro (FOIRN) em parceria com o Instituto Socioambiental (ISA), reportou mais de 300 lugares sagrados ${ }^{24}$ relacionados com as narrativas míticas dos povos da região (Andrello, 2012).

As referências sobre as experiências de mapeamento de SNS de povos indígenas reforçam a necessidade de promover a troca de conhecimentos entre as gerações, fomentando reflexões sobre a história dos povos e suas transformações, aliando o registro dos sítios sagrados à valorização das suas práticas rituais. Elas também indicam que há um grande interesse dos grupos em dar continuidade a esse tipo de projeto, ampliando a iniciativa para outras áreas. E que essas experiências contribuem não só para a sua valorização cultural, mas também respaldam processos de mobilização coletiva pela garantia de seus direitos sociais e territoriais.

Apesar da limitação de registros sobre os SNS indígenas, diversas notícias divulgadas na mídia destacam ameaças a esses locais, particularmente no contexto do licenciamento de empreendimentos vinculados a megaprojetos de infraestrutura (Ricardo \& Ricardo, 2006; 2011). Um caso emblemático foi a construção do Complexo Hidrelétrico de Belo Monte/PA, contestado, entre outros motivos, por incidir sobre lugares sagrados que possuem um alto valor cultural para as etnias da região.

Também há registros de SNS que sofreram ações de vandalismo e lugares que foram alvo de depredação por intolerância religiosa, especialmen- te contra grupos de matriz afrobrasileira. A literatura relata, ainda, confrontos envolvendo diferentes interesses no uso desses espaços, por exemplo, com indivíduos ou grupos que procuram essas áreas para lazer ou práticas esportivas (Brito, 2008; Malta, 2016). Essas situações têm levado alguns grupos sociais a demandar do poder público a implementação de estratégias de salvaguarda de seus SNS, com o tombamento dessas áreas como patrimônio cultural ou com a criação de parques municipais que reconheçam esses valores. Em outros contextos, são os próprios grupos sociais que buscam adquirir áreas dotadas de significados simbólicos para garantir o espaço de realização dos seus rituais (Malta, 2016).

Alguns monumentos católicos em áreas naturais foram tombados pelo Instituto do Patrimônio Histórico e Artístico Nacional do Brasil (IPHAN) em função do seu patrimônio arquitetônico, histórico ou paisagístico - como o Cristo Redentor/ RJ, o Santuário da Serra da Piedade/MG e a Toca do Boqueirão/PI. O instrumento do tombamento é comumente aplicado para a salvaguarda de bens culturais materiais que, muitas vezes, também possuem valores imateriais ou intangíveis associados - ainda pouco reconhecidos na aplicação dos instrumentos de políticas públicas no país.

No Brasil, o registro de bens culturais de natureza imaterial foi instituído somente no ano 2000 (pelo Decreto Federal N No. 3.551), incluindo ofícios e modos de fazer, formas de expressão e lugares onde se concentram e se reproduzem determinadas práticas. As Cachoeiras do Iauaretê/AM, mencionadas anteriormente, constituem o primeiro processo de salvaguarda de um bem imaterial relacionado a lugares sagrados no país, efetivado em

\footnotetext{
${ }^{24}$ Não contabilizados nesse artigo pela impossibilidade de especificá-los.
} 
2006 (IPHAN, 2008) ${ }^{25}$. Esse representa também um caso pioneiro de patrimonialização de bens culturais indígenas, marcando a ampliação da aplicação dessa política a grupos sociais historicamente colocados à margem das ações de preservação patrimonial (Jaenisch, 2011).

Essas iniciativas, entretanto, são pontuais e incipientes frente às potencialidades do território brasileiro quanto à ocorrência de sítios sagrados. Além disso, dadas as ameaças a que muitos desses lugares estão sujeitos, é necessário avançar na proposição de estratégias complementares para a proteção dos SNS no Brasil.

É interessante observar que, ainda que a relevância dos SNS para a proteção da natureza seja comumente destacada na literatura, alguns problemas que ameaçam esses sítios decorrem de restrições impostas pela legislação ambiental. A instalação de símbolos sacros como cruzeiros e estátuas em morros, por exemplo, e o acesso a esses locais, um hábito tradicional em países católicos, vem sendo coibida nas últimas décadas por regulamentações legais que protegem o topo dessas elevações (Brito, 2008). A visitação em cavernas está sujeita à autorização por parte dos órgãos ambientais e demanda, em tese, a elaboração de um plano de manejo - inclusive para uso religioso. Em outros locais, oferendas e objetos de cunho religioso deixados na natureza são alvo de ações fiscalizatórias e coercitivas por parte do Estado contra grupos religiosos (Malta, 2016).

O levantamento realizado indica também que diversos SNS estão associados a áreas protegidas legalmente instituídas pelo poder público - como o Morro do Corcovado/RJ, o Monte Roraima/RR e as Cataratas do Iguaçu/PR (situados em parques nacionais); a Gruta Pedra da Santa/PB, o Morro do Anhangava/PR e a caverna de Terra Ronca/GO (em parques estaduais); a Serra da Piedade/MG (um monumento natural estadual); entre outros. Esses registros reafirmam um cenário descrito na literatura internacional, de que há uma tendência global de inclusão de SNS, nas últimas décadas, nos limites de áreas protegidas, muitas vezes sem que seus valores culturais e espirituais sejam reconhecidos (Dudley et al., 2005; Wild \& McLeod, 2008). É relevante destacar, nesse contexto, que o Brasil é o país com maior número de áreas protegidas no mundo e que a relação entre os grupos sociais e os órgãos oficiais com competência na gestão das áreas também tem sido permeada por conflitos relacionados aos direitos de acesso e uso desses territórios (Lauriola, 2004; Mungai, 2008; Léo Neto, 2015; Sandroni \& Carneiro, 2016).

Os exemplos apresentados ilustram a variedade e a recorrência dos SNS no país, além de sua importância nas tradições de diversos grupos sociais e religiosidades. Os diferentes contextos geográficos e socioeconômicos nos quais os SNS estão inseridos e a multiplicidade de práticas realizadas nesses espaços podem resultar em diferentes implicações para a conservação da natureza, tanto positivas como negativas. Entretanto, são inúmeras as lacunas de informações sobre essas áreas, refletindo em desafios para a aplicação de políticas públicas voltadas para o seu manejo e proteção.

\footnotetext{
${ }^{25}$ Em 2010, dois outros lugares sagrados - relacionados ao Kuarup, uma cerimônia fúnebre ritualística compartilhada por povos indígenas do Alto Xingu/MT -, foram tombados como patrimônio cultural do Brasil (Fonte: Portal do IPHAN).
} 


\section{Entre o conhecimento cientifico e o popular: construindo um objeto de estudo}

A maior parte da literatura especializada produzida sobre a temática dos SNS vem sendo redigida em inglês, com algumas traduções para o espanhol e o francês. Publicações em português sobre o assunto são escassas e a expressão sitios naturais sagrados ainda não é usual no país. As primeiras referências brasileiras a fazer uso desse termo, de acordo com o levantamento realizado, são relativamente recentes e estão concentradas - em sua maioria - nos últimos cinco anos.

Até onde foi possível pesquisar, a dissertação de mestrado de Moutinho-da-Costa (2008) foi a primeira referência a fazer uso da expressão sítios naturais sagrados na bibliografia nacional. Destacam-se também os artigos publicados em anais de eventos acadêmicos por Corrêa et al. (2013) e Fernandes-Pinto \& Irving (2015a - este o primeiro a mencionar o termo no título); e os artigos publicados em periódicos científicos por Lazzerini \& Bonotto (2014) e Fernandes-Pinto \& Irving (2017).

A adoção dessa expressão, no entanto, não delimita os estudos sobre o tema no país, abordado historicamente por diversos campos acadêmicos. Alguns termos que exprimem conotações similares utilizadas nas publicações brasileiras são lugar sagrado, geossímbolo e sítios de pertencimento noções imbricadas especialmente com os estudos da Geografia Cultural. Além desse campo de conhecimento, a análise da literatura indica que os SNS vêm sendo estudados no Brasil principalmente a partir de pesquisas qualitativas de áreas das Ciências Humanas e Sociais como História, Antropologia, Sociologia, Teologia e Psicologia Social.
A descrição e a interpretação dos processos histórico-culturais por meio dos quais os sítios vêm sendo sacralizados e transformados em lugares de manifestações religiosas constitui o principal foco das pesquisas identificadas. Outra abordagem de destaque consiste na investigação da relação entre lugares sagrados e a atividade turística, particularmente do segmento denominado turismo religioso (Oliveira, 2011). A interface com a preservação do patrimônio cultural também é um tema recorrente, notadamente no campo da Geografia das Religiões, incluindo estudos sobre a difusão e distribuição das tradições, a delimitação de espaços sagrados e a influência da religiosidade nos deslocamentos humanos (Rosendahl, 1996; Corrêa \& Rosendahl, 2004). A produção acadêmica que busca refletir sobre o uso religioso do patrimônio geológico e paleontológico também vem se ampliando nos últimos anos (Delphim, 2009), com destaque para a relevante produção nacional sobre cavernas, seus simbolismos e usos religiosos (Travassos et al., 2011).

Apesar das evidências da interface desse tema com o patrimônio natural, reflexões dessa natureza ainda são escassas nas pesquisas desenvolvidas no território nacional. As referências compiladas salientam, em geral, os impactos negativos das práticas religiosas na natureza e os conflitos envolvendo as áreas protegidas (Brito, 2005; Cavalcante, 2007; Campos et al., 2008), sendo raras as menções às potencialidades e benefícios do reconhecimento desses valores.

Os resultados indicam, de maneira geral, um predomínio na literatura analisada de referências a SNS vinculados ao catolicismo e uma menor incidência de registros relacionados a outras religiosidades. É importante mencionar que, apesar 
do declínio do número de praticantes dessa religião nas últimas décadas - e da diversificação de linhas religiosas praticadas no país -, o Brasil ainda é majoritariamente católico ${ }^{26}$ e essa hegemonia se reproduz em várias esferas da sociedade, inclusive na pesquisa acadêmica.

Em função disso, autores que investigam a importância cultural de determinados elementos da natureza (como as cavernas, por exemplo), vêm questionando se o uso desses espaços por tradições não católicas seria realmente incomum ou apenas menos documentado nas pesquisas, devido ao preconceito ainda existente no país em relação a algumas dessas religiosidades (Guimarães et al., 2011). Na Geografia das Religiões também evidencia-se uma predominância de estudos sobre o catolicismo, de forma que alguns autores reforçam a necessidade de ampliar as investigações para outras matrizes religiosas (Arantes, 2014; Malta, 2016). Os movimentos contemporâneos das religiosidades alternativas, particularmente, representam um nicho ainda pouco explorado na reflexão acadêmica sobre o tema, inclusive na literatura internacional.

Essas observações também se aplicam aos povos indígenas e outras populações tradicionais, cujos registros de SNS no Brasil possivelmente estejam subestimados, principalmente considerando que as experiências pioneiras de mapeamento neste campo testemunham a relevância desses locais nas suas cosmologias e na conformação dos seus territórios (Andrello, 2012; Scolfaro et al., 2014).

É importante considerar que uma das características mais marcantes dos SNS diz respeito à relação subjetiva que determinados grupos sociais têm com esses lugares, que não devem ser interpretados somente como sítios físicos, pois conjugam saberes e fazeres dos seus guardiões. Esses podem inclusive residir a uma distância considerável dos sítios, mantendo-se conectados a eles por meio das histórias transmitidas entre gerações e das suas práticas espirituais - uma situação que parece ser comum no contexto brasileiro. Além disso, os SNS não representam elementos estáticos no tempo e no espaço, estando sujeitos a processos - internos ou externos - dinâmicos, que incluem possibilidades de destruição, abandono e esquecimento, por um lado, e de revitalização e ressignificação, por outro.

Outro aspecto relevante a ser observado consiste na avaliação de que a maior parte das informações compiladas sobre os SNS no Brasil, no levantamento realizado, foi proveniente de fontes não convencionais à pesquisa acadêmica clássica e que não são apreendidas por consulta em bases indexadoras de publicações científicas. De fato, apenas $17 \%$ das referências compiladas correspondem a artigos publicados em periódicos. A maioria dos registros consiste em notícias de jornais, revistas e sites da internet (20\%); livros e capítulos de livros (19\%); teses, dissertações e monografias (18\%); anais de eventos técnico-científicos (12\%); publicações de agências governamentais, de organizações não governamentais, boletins eletrônicos de sociedades científicas ou revistas de divulgação (7\%) e outras não classificadas (7\%). Esse tipo de material - não indexado em bases bibliográficas científicas - vem sendo denominado de grey literature ou

\footnotetext{
${ }^{26}$ Segundo dados do último censo demográfico nacional, cerca de $68 \%$ da população se declarou ligada ao catolicismo. O Brasil possui o maior contingente de católicos no mundo. Essa foi a religião oficial do Estado até a promulgação da Constituição Republicana de 1891, que adotou o Estado laico (Neri, 2011).
} 
literatura cinzenta, um conceito que começou a se consolidar internacionalmente a partir da década de 1970, especialmente na Europa e nos Estados Unidos, ainda pouco explorado no Brasil.

Esse quadro merece uma reflexão mais aprofundada no contexto deste estudo. Isso porque, apesar das diversas ressalvas sobre o padrão de qualidade, credibilidade dos dados e mérito científico desses documentos, a literatura cinzenta vem sendo reconhecida como uma importante via de conhecimento sobre temas de alta relevância para a ciência. A facilidade de acesso e circulação das informações - principalmente com o crescimento dos acervos digitais - são aspectos positivos enfatizados para o uso desse tipo de material na construção de novos conhecimentos ${ }^{27}$. Além disso, devido ao elevado padrão de qualidade comumente exigido para os artigos em periódicos indexados ${ }^{28}$ - somado ao tempo de análise das submissões até a efetiva publicação (de até dois anos) e o fato de muitas plataformas não serem de acesso livre -, os resultados de diversos estudos relevantes para a construção de um dado campo de conhecimento podem não ser disponibilizados por essa via, tornando a literatura cinzenta uma fonte preciosa de informações muitas vezes inéditas, como observado no levantamento realizado sobre os SNS no Brasil. Além disso, na literatura cinzenta são comumente encontradas descrições mais detalhadas dos fenômenos estudados - especialmente em teses e dissertações - do que em artigos científicos, que têm limitações quanto ao número de páginas que comportam (Auger, 1989; Población, 1992; Gomes et al., 2000).

Esses fatores explicam, em parte, a carência de informações sobre os sítios naturais sagrados brasileiros nas bases de dados internacionais sobre o tema, pois os autores estrangeiros nem sempre têm acesso à literatura cinzenta, produzida quase que exclusivamente no idioma português. Entretanto, um outro aspecto que favorece essa situação consiste no fato da literatura internacional especializada na temática - bem como as recomendações e diretrizes propostas nas últimas décadas em eventos globais de referência - praticamente não serem mencionadas nas publicações nacionais. Essa representa uma importante lacuna nas pesquisas realizadas sobre o tema no país, evidenciando uma desconexão com a discussão internacional mais ampla e a falta de vinculação com o debate global em políticas públicas. Esses, no entanto, não parecem ser os únicos aspectos envolvidos na questão, uma vez que também se identifica essa lacuna de informações nas publicações internacionais para a maioria dos países latinoamericanos.

Seja pela dificuldade de tradução idiomática ou pela incipiente participação de pesquisadores brasileiros nos fóruns globais ${ }^{29}$, esses fatores também contribuem para a invisibilidade dos sítios naturais sagrados brasileiros no cenário mundial ${ }^{30}$. Diante desse quadro, a adoção da expressão sítios

\footnotetext{
${ }^{27}$ Nas publicações exclusivamente on-line, entretanto, o acesso a longo prazo dos documentos pode não ser mantido - um problema mencionado por alguns autores como apodrecimento do link.

${ }^{28}$ Entendidos como aqueles que abrangem uma ou mais áreas de conhecimento, editados com periodicidade regular, que possuem um corpo editorial constituído e cujos artigos são credenciados por revisores especializados, a partir de critérios de avaliação da sua estrutura e qualidade (UFPR, 2007).

${ }^{29}$ Como evidenciado quando da participação em alguns deles, notadamente nos últimos congressos mundiais da IUCN.

${ }^{30}$ Uma abordagem mais aprofundada sobre isso é necessária e pode indicar padrões de colonialidade do saber e desequilíbrios entre as episte
} 
naturais sagrados neste artigo - ainda que não usual nas publicações nacionais e problemática do ponto de vista teórico/conceitual - se justifica pelo intuito de promover a conexão das pesquisas realizadas no país com o debate mundial em cur$\mathrm{so}^{31}$. É importante considerar, ainda, que esse termo permite uma conceituação abrangente, aplicável aos valores espirituais da natureza expressos por diversos grupos sociais, para além das religiões majoritárias - o que também consiste em uma necessidade premente no contexto da diversidade religiosa e cultural brasileira.

Sob o paradigma da modernidade, a visão de dualidade entre cultura e natureza vem resultando em uma visão fragmentada da realidade tanto nas pesquisas acadêmicas como na formulação de políticas públicas. Assim, no cerne dessa reflexão emerge a necessidade de se avançar no reconhecimento da interdependência dessas dimensões. No estudo dos SNS, é primordial que se busque a compreensão desse fenômeno a partir de um olhar integrado da natureza, dos grupos sociais, seus conhecimentos e suas práticas como elementos indissociáveis de uma equação única. Esta consiste em uma temática complexa, que demanda investigações construídas a partir de perspectivas interdisciplinares e abordagens teóricas capazes não somente de promover o diálogo do conhecimento científico com a sabedoria popular, como também de desconstruir essas dicotomias.

\section{Considerações finais: novos horizontes a serem desvelados}

Conforme retratado nesse artigo, os SNS do Brasil incluem uma grande variedade de feições morfológicas, presentes tanto na terra como nas águas interiores e áreas costeiro-marinhas. Os resultados revelam que a recorrência da manifestação desse fenômeno nas diversas regiões do país e a sua importância para muitos grupos sociais contrastam com o seu incipiente reconhecimento nas políticas públicas. Além disso, as referências bibliográficas sobre o tema estão em sua maior parte dispersas em publicações não indexadas, permeando uma ampla gama de estudos de múltiplas áreas de conhecimento, em geral desconectadas do debate internacional.

A estratégia da Rede SNS Brasil foi essencial para ampliar os registros e aprofundar a reflexão sobre o tema, permitindo o acesso a fontes diversificadas de informações sobre o assunto e a mobilização de uma rede de interlocutores para difusão das investigações realizadas nesse sentido no Brasil. Essa iniciativa, ainda que embrionária, indica a potencialidade da pesquisa colaborativa na construção de novos conhecimentos - uma metodologia ainda pouco utilizada nas abordagens acadêmicas convencionais, alinhada com as premissas de uma ciência cidadã $\tilde{a}^{32}$.

É importante considerar, entretanto, que muitas referências sobre o tema podem ainda perma-

mologias do Norte e do Sul, inclusive em meio a grupos e organizações que buscam romper com essas premissas.

${ }^{31}$ Um primeiro esforço nessa direção foi realizado com a apresentação do trabalho intitulado Sacred Natural Sites in Brazil: a collaborative research, no World Conservation Congress da IUCN realizado em setembro de 2016, em Honolulu/Havaí (Disponível em: https://portals.iucn. org/congress/session/10000).

${ }^{32}$ Perspectiva que considera a ciência como ferramenta de cidadania, o cidadão como um potencial agente científico e os resultados de pesquisa como um bem público (Fonte: http://www.movimentocienciacidada.org/manifesto). 
necer ocultas, não tendo sido detectadas pelas vias metodológicas utilizadas no presente levantamento. Considerando a riqueza socioambiental do país, presume-se que ainda há muito a ser desvendado sobre esse assunto. Isso é particularmente relevante no caso de SNS associados a povos indígenas e outras populações tradicionais, segmentos que representam a principal lacuna na investigação acadêmica sobre o tema.

Por esses motivos, reconhece-se a importância da continuidade desse inventário e da diversificação das estratégias de pesquisa, de forma a contemplar tanto a revisão de material bibliográfico como o registro de informações primárias. Neste segundo caso, entrevistas com interlocutores estratégicos e estudos de campo em áreas de potencial ocorrência de SNS são alguns caminhos possíveis indicados na literatura especializada sobre o tema. Além disso, a estruturação de uma plataforma virtual que permita o registro direto de SNS por pesquisadores e/ou representantes de grupos sociais também se configura como uma ferramenta viável para dar seguimento à pesquisa colaborativa iniciada com a Rede SNS Brasil.

Para que seja possível avançar na formulação de políticas públicas e no planejamento de ações concretas para o manejo e a salvaguarda dessas áreas, entretanto, é essencial que se avance na construção de uma ação mais ampla e articulada de investigação aliada à intervenção - aproximando instituições de pesquisa, agências governamentais, organizações da sociedade civil e movimentos sociais. Nessa direção, a continuidade dos estudos sobre os SNS no Brasil deve abranger uma descrição mais detalhada das suas características socioambientais, o status legal de dominialidade das áreas, seu estado de conservação, problemas e ameaças, entre outros. Além disso, é importante observar que o registro de dados primários sobre SNS - conforme preconizam as normativas internacionais sobre o tema - deve garantir o direito dos guardiões tradicionais à confidencialidade sobre a localização e função dos seus sítios (se assim desejarem) e ao consentimento prévio e informado sobre qualquer intervenção que reflita sobre eles.

Considerando também que muitos desses sítios estão em áreas protegidas, é essencial que se avance no reconhecimento e na reflexão não apenas sobre a importância social do fenômeno, como também sobre as suas implicações nas estratégias de proteção da natureza. Garantir o protagonismo dos guardiões tradicionais na tomada de decisões sobre as regras de uso e manejo desses lugares vem sendo um dos principais temas das discussões mundiais sobre o assunto. Entretanto, não se pode negar que o uso religioso em áreas naturais pode acarretar em diversos impactos negativos para a sua conservação, e que estes não devem ser desconsiderados.

Diante da evidente escassez de informações sobre os SNS do Brasil na literatura especializada e no debate global sobre o tema, testar a aplicabilidade das diretrizes internacionais para o manejo de sítios sagrados e avaliar a sua adequação ao quadro jurídico nacional são passos necessários para promover essa aproximação. Além disso, essa lacuna somente será superada com o fomento à publicação e tradução dos resultados das pesquisas nacionais para outros idiomas, especialmente para o inglês, e com a participação de representantes nacionais nos fóruns e eventos globais. Nessa direção, é importante ressaltar que as informações compiladas sobre SNS no Brasil nesse levantamento exploratório possivelmente colocam o país em uma 
posição proeminente com relação a essa temática no cenário mundial.

Sem pretender esgotar o debate sobre um tema tão rico e instigante, buscou-se, com este artigo, despertar a atenção para a importância dos SNS no cenário brasileiro, delineando-os como objeto de estudo científico e de aplicação de políticas públicas. A pesquisa sobre sítios naturais sagrados apresenta um relevante potencial no país, ao revelar uma faceta em grande parte ainda desconhecida do seu patrimônio, vinculada à configuração da própria identidade nacional. Por fim, lança-se um convite à ação e à formação de alianças que contribuam com a missão de desvelar os encantos e os mistérios das dimensões sagradas da natureza na terra brasilis. A jornada, afinal, continua...

\section{Agradecimentos}

Aos colaboradores da Rede SNS Brasil que participam da aventura de descobrir os sítios naturais sagrados no Brasil. Ao Instituto Chico Mendes de Conservação da Biodiversidade e ao Programa EICOS de Pós-Graduação da Universidade Federal do Rio de Janeiro, pelo apoio e oportunidade de realizar esse trabalho.

\section{Referências}

Afonso, G. B.; Nadal, C. A. Arqueoastronomia no Brasil. In: Matsuura, O. T. (Org.). História da Astronomia no Brasil 2013. v.1. p. 52-86, 2014.

Amado, R. Festa nas Águas: fé e tradição nos rios e mares do Brasil. São Paulo: Ed. Horizonte, 2011.

Amaral, L. Carnaval da alma: Comunidade, essência e sincretismo na Nova Era. Petrópolis: Vozes, 2000.
Andrello, G. (Org.). Rotas de criação e transformação: narrativas de origem dos Povos Indígenas do Rio Negro. São Paulo: Instituto Socioambiental, 2012.

Arantes, M. M. O território religioso do Vale do Amanhecer: um relato histórico, político e cultural. Ateliê Geográfico, 8(1), 231-251, 2014.

Auger, C. P. (Ed.). Information Sources in Grey Literature. London: Bowker Saur, 1989.

Boff, L. Ecologia, Mundialização, Espiritualidade. Rio de Janeiro: Record, 2008.

Bond, R. História do Caminho de Peabiru: descobertas e segredos da rota indígena que ligava o Atlântico ao Pacífico. V.1. Rio de Janeiro: Aimberê, 2009.

Brito, A. G. O cerco à natureza: o simbolismo e as conflitantes formas de apropriação presentes no Morro do Anhangava (Quatro Barras - PR). Curitiba, Monografia (Geografia) - UFPR, 2005.

Brito, A. G. As montanhas e suas representações através dos tempos: buscando significados. Curitiba, Tese (Doutorado) - UFPR, 2008.

Campos, A.; Santana, D. S.; Luiz, V. Turismo em unidades de conservação: propostas para o Parque Estadual do Monge - Lapa/PR. Curitiba, TCC - Faculdades Integradas Santa Cruz, 2008.

Carmichael, D. L.; Hubert, J.; Reeves, B.; Schanche, A. (Eds.). Sacred Sites, Sacred Places. London: One World Archeology, 1994.

Carvalho, I. C. M.; Steil, C. A. A sacralização da natureza e a 'naturalização' do sagrado: aportes teóricos para a compreensão dos entrecruzamentos entre saúde, ecologia e espiritualidade. Ambiente \& Sociedade, XI(2), 289-305, 2008.

Cavalcante, M. B. Parque Estadual da Pedra da Boca/PB: um olhar sobre o planejamento do ecoturismo em unidades de conservação na Paraíba. OKARA, 1(2), 62-78, 2007.

Corrêa, R. L.; Rosendahl, Z. Country reports: Brazilian studies in cultural geography. Social \& Cultural Geography, 5(4), 651-662, 2004.

Corrêa, A. M; Costa, L.; Loureiro, C. F. O processo de implantação do espaço sagrado em unidade de conservação: o 
caso da Curva do S no Parque Nacional da Tijuca na cidade do Rio de Janeiro. In: Anais 14 EGAL. Peru, 2013.

Correia, R. L. L. S. Territorialidades, patrimônio e conservação na Serra da Barriga, sede do antigo Quilombo dos Palmares. In: IV REA. Fortaleza, 2013.

Corso Neto; T.; Soares, T. D. O valor cultural do encontro das águas entre os rios Negro e Solimões como fundamento para o seu tombamento. In: Marés Filho, C. F.; Campello, L. G. B.; Padilha, N. S. Direito ambiental e socioambientalismo. Florianópolis: CONPEDI, 2015.

Delphim, C. F. M. Patrimônio Cultural e Geoparque. Geologia USP, 5, 75-83, 2009.

Dudley, N.; Higgins-Zogib, L.; Mansourian, S. Beyond Belief: linking faiths and Protected Areas to support biodiversity conservation. Cambridge: WWF, 2005.

Eliade, M. O Sagrado e o Profano: a essência das religiões. São Paulo: Martin Fontes, 2010.

Favera, J. C. D. Parque Nacional de Sete Cidades, PI: magnífico monumento natural. SIGEP 25. 335-342. In: Schobbenhaus, C.; Campos, D. A.; Queiroz, E. T.; Winge, M.; Berbert-Born, M. L. C. (Eds.) Sítios geológicos e paleontológicos do Brasil. V.1. Brasília: DNPM/CPRM, 2002.

Fernandes-Pinto, E. Sítios Naturais Sagrados do Brasil: inspirações para o reencantamento das áreas protegidas. Tese (Doutorado em Psicossociologia e Ecologia Social - UFRJ, 2017. Disponível em: https://goo.gl/ZNCE11

Fernandes-Pinto, E.; Irving, M. A. Sítios Naturais Sagrados no Brasil: o gigante desconhecido. In: Hanazaki, N.; Herbst, D. F.; Ávila, J. V. C.; Heineberg, M. R.; Gomes, T. C. C. (Orgs.). Culturas e Biodiversidade: o presente que temos e o futuro que queremos. Anais do VII SAPIS e II ELAPIS, Florianópolis: UFSC. p. 397-408, 2015a. Disponível em: http://sapiselapis2015.paginas.ufsc.br/2015/11/18/anais-do-vii-sapis-e-ii-elapis/

Fernandes-Pinto, E.; Irving, M. A. Valores Culturais e Espirituais do Parque Nacional do Monte Roraima/RR: um horizonte inexplorado. In: Anais do IV CONINTER. Foz do Iguaçu, 2015b. Disponível em: http://www.aninter.com.br/ Anais\%20Coninter\%204/g9.html

Fernandes-Pinto, E.; Irving, M. A. Sítios Naturais Sagrados: valores ancestrais e novos desafios para as políticas de proteção da natureza. Desenvolvimento e Meio Ambiente, 40, 275-296, 2017. Disponível em: http://revistas.ufpr.br/ made/article/view/47843

Ferretti, M. Lugares Sagrados e Encantarias Maranhense. Boletim da Comissão Maranhense do Folclore, 40, 3-4, 2008 .

Gomes, S. L. R.; Mendonça, M. A. R.; Souza, C. M. Literatura Cinzenta. In: Campello, B. S.; Cendón, B. V.; Kremer, J. M. (Orgs.). Fontes de informação para pesquisadores e profissionais. Belo Horizonte: UFMG, 2000.

Guimarães, E.; Pellin, A. BiodiverCidade: desafios e oportunidades na gestão de áreas protegidas urbanas. São Paulo: Matrix, 2015.

Guimarães, R. L.; Travassos, L. E. P.; Varela, I. D. Cavernas e rituais afro-brasileiros em Minas Gerais. p. 351-372. In: Travassos, L. E. P.; Magalhães, E. D.; Barbosa, E. P. (Orgs.). Cavernas, rituais e religião. Ilhéus: UESC, 2011.

Harmon, D.; Putney, A. D. The full values of parks: from economics to the intangible. Maryland: Rowman and Littlefield, 2003.

IPHAN - Instituto do Patrimônio Histórico e Artístico Nacional. Cachoeira de Iauaretê: lugar sagrado dos povos indígenas dos Rios Uaupés e Papuri (AM). Dossiê 7. 2008.

Jaenisch, D. B. Política brasileira de patrimônio imaterial: apontamentos sobre o registro e salvaguarda de dois bens culturais indígenas. Mouseion, 10, 96-107, 2011.

Jeanrenaud, S. An international initiative for the protection of sacred natural sites and other places of indigenous and traditional peoples with importance for biodiversity conservation. WWF International, 2001.

Karsburg, A. O. O Eremita do Novo Mundo: a trajetória de um peregrino italiano na América do século XIX (18381869). Tese (Doutorado em História Social) - UFRJ, 2012.

Kopenawa, D.; Albert, B. A queda do céu: palavras de um xamã Yanomami. Cia. das Letras, 2015.

Labate, B. C. A reinvenção do uso da ayahuasca nos centros urbanos. Dissertação - UNICAMP, 2000.

Labate, B. C.; Goulart, S. L. O uso ritual das plantas de 
poder. Campinas: Mercado das Letras e Fapesp, 2005.

Lauriola, V. Parque Nacional? Kaané! Os índios dizem não à implementação do Parque Nacional do Monte Roraima. In: Ricardo, F. (Org.); Terras Indígenas e Unidades de Conservação da natureza: o desafio das sobreposições. São Paulo: ISA, p. 422-431, 2004.

Lazzerini, F. T.; Bonotto, D. M. Fontes de águas "milagrosas" no Brasil. Ciência e Natura, 36, 559-572, 2014.

Leite, M. C. S. No Reino das Águas: encantados, natureza e cultura do Pantanal. 2000.

Léo Neto, N. A. "Nós somos os donos": conflitos socioambientais entre os índios Pipipã de Kambixuru e o ICMBIO no sertão de Pernambuco. In: REA, 2015.

Lewinsohn, T. M.; Prado, P. I. Quantas espécies há no Brasil? Megadiversidade, 1(1), 36-42, 2005.

Lima, J. A Y-Guazu secreta: Cataratas do Iguaçu como Chackra da Terra. Foz do Iguaçu, 2005.

Maciel, G. G.; Gonçalves, R. S. Unidades de conservação, práticas religiosas neopentecostais e direitos humanos: $\mathrm{o}$ caso do Parque Nacional da Tijuca (RJ). In: Hanazaki, N.; Herbst, D. F.; Ávila, J. V. C.; Heineberg, M. R.; Gomes, T. C. C. (Orgs.). Culturas e Biodiversidade: o presente que temos e o futuro que queremos. Anais do VII SAPIS e II ELAPIS, Florianópolis: UFSC. p. 397-408, 2015.

Magalhães, J. A. A romaria da terra e das águas de Bom Jesus da Lapa/BA: (re)invenção do religioso e do político. Dissertação - UFBA, 2010.

Malta, R. R. A significância religiosa do Parque Nacional da Tijuca: as paisagens valorizadas pelos usuários religiosos de uma unidade de conservação. Tese - UERJ, 2016.

Marques, J. G. W. Da gargalhada ao pranto: Inserção Etnoecológica da vocalização de aves em ecossistemas rurais do Brasil. Tese - UEFS, 1999.

Marques, J. G. W. Pescando pescadores: etnoecologia abrangente no baixo São Francisco. São Paulo: NUPAUB-USP, 2001.

Moutinho-da-Costa, L. A Floresta sagrada da Tijuca: estudo de caso de conflito envolvendo uso público religioso de parque nacional. Dissertação - UFRJ, 2008.
Mungai, M. F. Mosaico de interesses, representações e conflitos: o Parque Nacional Cavernas do Peruaçu - MG. Dissertação - UFMG, 2008.

Neri, M. C. (Org.). Novo Mapa das Religiões. Rio de Janeiro: FGV, 2011.

Oliveira, C. D. M. Festas religiosas, santuários naturais e vetores de lugares simbólicos. Revista da ANPEGE, 7(8), 93-106, 2011.

Oliveira, E. G. S. Os Índios Pankará na Serra do Arapuá: relações socioambientais no Sertão pernambucano. Dissertação (Mestrado em História) - UFCG, 2014.

Población, D. A. Literatura cinzenta ou não convencional: um desafio a ser enfrentado. Ciência da Informação, 21(3), 243-246, 1992.

Prandi, R. (Org.). Encantaria Brasileira: o livro dos mestres, caboclos e encantados. Rio de Janeiro: Pallas, 2004.

Ricardo, B.; Ricardo, F. (Eds.). Povos Indigenas no Brasil: 2001/2005. São Paulo: Instituto Socioambiental, 2006.

Ricardo, B.; Ricardo, F. (Eds.). Povos Indígenas no Brasil: 2006-2010. São Paulo: Instituto Socioambiental, 2011.

Ricardo, B.; Ricardo, F. (Eds.). Povos Indigenas no Brasil: 2011-2016. São Paulo: Instituto Socioambiental, 2017.

Rosendahl, Z. Espaço \& Religião: uma abordagem geográfica. Rio de Janeiro: UERJ, 1996.

Sandroni, L. T.; Carneiro, M. J. T. "Conservação da Biodiversidade" nas Ciências Sociais Brasileiras: uma revisão sistemática de 1990 a 2010. Ambiente \& Sociedade, XIX(3), 21-46, 2016.

Santos, J. S.; Brito, V. Abrigos rochosos e sepultamentos pré-históricos na Paraíba. In: Travassos, L. E. P.; Magalhães, E. D.; Barbosa, E. P. (Orgs.). Cavernas, rituais e religião. Ilhéus: Editus, p. 163-174, 2011.

Schaaf, T. UNESCO's experience with the protection of sacred natural sites for biodiversity conservation. In: Lee, C., Schaaf, T. The Importance of Sacred Natural Sites for Biodiversity Conservation. Paris: UNESCO-MAB, 2003.

Scolfaro, A.; Oliveira, A. G.; Hernández, N.; Gómez, S. (Orgs.). Cartografia dos sítios sagrados: iniciativa bina- 
cional Brasil-Colômbia. Primeiro Informe de Avanços. São Paulo: ISA; Brasília: IPHAN/Ministério da Cultura do Brasil; Bogotá: Ministério da Cultura da Colômbia, 2014.

Silva, G. "Chama os Atikum que eles desatam já": práticas terapêuticas, sabedoria e poder. Dissertação (Mestrado em Antropologia) - UFPE, 2007.

Siqueira, D. E. Biodiversidade, Estado brasileiro e Religião na Amazônia. Horizonte, 8(17), 56-78, 2010.

Siqueira, D.; Bandeira, L. Misticismo no Planalto Central: a Chapada dos Veadeiros, 'chackra cardíaco do planeta'. In: Duarte, L. M. G. (Org.). Tristes Cerrados. Sociedade e Diversidade. Brasília: Paralelo 15, 1998.

Sobreira, R. F. F.; Machado, C. J. S. Práticas religiosas afro-brasileiras, marco regulatório e uso do meio ambiente e do espaço urbano da cidade do Rio de Janeiro. Revista Visões, 1(5), 2008.

Steil, C. A. O sertão das romarias: um estudo antropológico sobre o Santuário de Bom Jesus da Lapa-Bahia. Petrópolis: Vozes, 1996.

Steil, C. A.; Carneiro, S. S. Peregrinação, turismo e Nova Era: caminhos de Santiago de Compostela no Brasil. Religião e Sociedade, 28(1), 105-124, 2008.

Tavares, J. M.; Vieira-Jr., J. A. V.; Batista, J. R. M. Circuito Montanhas Mágicas da Serra da Mantiqueira (Minas Gerais - Brasil): uma análise multidimensional. Pasos, 9(4), 661-670, 2011.
Thorley, A.; Gunn, C. M. Sacred Sites: an overview. London: The Gaia Foundation, 2007. Disponível em: http:// sacrednaturalsites.org/wp-content/uploads/2011/10/Sacred_Sites_An_Overview.pdf

Travassos, L. E. P.; Magalhães, E. D.; Barbosa, E. P. (Orgs.). Cavernas, rituais e religião. Ilhéus: Editus, 2011.

UFPR - Universidade Federal do Paraná. Tutorial de Pesquisa Bibliográfica. Curitiba: UFPR, 2007.

UNESCO - United Nations Educational, Scientific and Cultural Organization. Natural Sacred Sites: cultural diversity and biological diversity International Symposium. 89 p. Abstracts. Paris, 1998.

Valle, C. N. Txopai Itohã: mito fundador pataxó. Acta Scientiarum, 23(1), 61-68, 2001.

Verger, P. Notas sobre o culto aos orixás e voduns na Bahia de Todos os Santos, no Brasil e na Antiga Costa dos Escravos, na África. São Paulo: EDUSP, 1999.

Verschuuren, B.; Wild, R.; McNeely, J.; Oviedo, G. (Eds.). Sacred Natural Sites: conserving nature and culture. Gland, Suíça: IUCN, 2010.

Weber, M. Ciência e Politica: duas vocações. Cultrix, 2004.

Wild, R.; McLeod, C. Sitios Sagrados Naturales: Directrices para Administradores de Áreas Protegidas. Gland: IUCN, 2008. Disponível em: https://www.iucn.org/es/content/ sitios-naturales-sagrados-directrices-para-administradores-de-áreas-protegidas 